\title{
PERFIS DE TEMPERATURA E UMIDADE DURANTE A SECAGEM DA NOZ DE MACADÂMIA
}

\author{
F. M. R. SILVA ${ }^{1}$, L. ARRIECHE ${ }^{2}$ e D. J. M. SARTORI ${ }^{3}$ \\ ${ }^{1}$ Aluno, Universidade Federal do Espírito Santo, Departamento de Engenharias e Tecnologia \\ ${ }^{2}$ Professor, Universidade Federal do Espírito Santo, Departamento de Engenharias e Tecnologia \\ ${ }^{3}$ Professor, Universidade Federal de São Carlos, Departamento de Engenharia Química \\ E-mail para contato: fernando_mrs@hotmail.com
}

RESUMO - A secagem é fundamental na conservação das qualidades nutricionais de produtos agrícolas. Neste sentido, este trabalho teve como foco a modelagem matemática da secagem, por convecção natural, da noz de macadâmia maltada. Por meio de balanços de massa e energia, em coordenadas esféricas, foram desenvolvidos modelos para simular os perfis de temperatura e umidade. As equações para os fenômenos de transferência de calor e de massa entre o ar de secagem e as amostras foram obtidas do modelo de Fourier e de Fick, considerando a difusividade efetiva de massa e a condutividade térmica como funções do tempo e da umidade. As equações foram solucionadas pelos métodos de diferenças finitas e Runge Kutta, com auxílio do MatLab. O modelo matemático apresentou um bom ajuste aos dados experimentais da cinética de secagem da noz de macadâmia, representando os perfis de temperatura e de umidade. $\mathrm{O}$ estudo foi importante para avaliar as condições de secagem e será adaptado para a etapa de torrefação do fruto.

\section{INTRODUÇÃO}

A secagem é uma das mais usuais operações unitárias encontradas nos mais diversos processos usados em vários setores da indústria. Na indústria alimentícia, o principal objetivo da secagem é a manutenção das qualidades do produto (Corrêa, 2007). Porém é operação unitária complexa que possui sub-processos envolvidos como o encolhimento da estrutura e os fenômenos internos e externos de transferência de calor e massa, os quais estão presentes na secagem de diversos materiais e que determinam a integridade física do produto final (Arrieche, 2007).

Durante a secagem é necessário um fornecimento de calor para evaporar a umidade do material e também deve haver um sorvedouro de umidade para remover o vapor água, formado a partir da superfície do material a ser seco (Roberts, 2003). Dois fenômenos ocorrem simultaneamente neste processo: transferência de energia do ambiente para evaporar a umidade superficial e transferência de massa do interior para a superfície do material. Ambos os fenômenos dependem das condições externas como temperatura, velocidade e umidade do ar de secagem e também das propriedades do material, como porosidade, difusividade e conteúdo de água. $\mathrm{O}$ aquecimento excessivo da amostra pode causar a caramelização ou decomposição dos açúcares, perda de voláteis ou ainda a oxidação dos lipídeos (Roberts, 2003). 
Com o auxílio da modelagem matemática da transferência de massa e de calor, por meio de experimentos em laboratório e, tendo em vista contribuir com os estudos neste sentido, o objetivo deste trabalho é a modelagem da transferência de calor e de massa da secagem da noz de macadâmia maltada em uma estufa, a fim de se obter uma metodologia adequada e consistente, representar o equilíbrio do sistema noz-água-ar e verificar a influência da temperatura e da umidade na cinética de secagem.

\section{MATERIAIS E MÉTODOS}

\subsection{Preparação das Amostras}

Sementes verdes e maduras com quebra de dormência, sem rachadura, com e sem broto foram selecionadas e separadas em três conjuntos distintos. A massa de cada conjunto foi medida e cada um dos seus elementos fotografados. Em seguida, as amostras foram colocadas em uma estufa (modelo $\mathrm{S} 250 \mathrm{SD}$ ) a 70 graus Celsius, onde permaneceram em intervalos de 15 minutos. O procedimento foi repetido até que a variação da massa não fosse significativa. Para a determinação da umidade de equilíbrio, as amostras permaneceram dentro da estufa a 105 graus Celsius por aproximadamente 12 horas.

\subsection{Metodologia}

O modelo de Fourier e de Fick foram avaliados em coordenadas esféricas e por meio de balanços de energia e massa, respectivamente, assumindo regime transiente. Ainda foram considerados que o fluido escoa em torno da amostra sem grandes perturbações e que a condutividade térmica e a difusividade não variam com o raio da amostra. A transferência de calor do ar de secagem para o interior do sólido e a transferência de massa da superfície do sólido para o ar de secagem podem, respectivamente, serem representadas pelas Equações 1 e 2 .

$$
\begin{aligned}
& \frac{\partial \theta}{\partial \tau}=\frac{R_{S}}{R^{2} \xi^{2}} \frac{\partial}{\partial \xi}\left[\xi^{2} \frac{\partial \theta}{\partial \xi}\right] \\
& \frac{\partial \psi}{\partial \tau^{\prime}}=\frac{R_{s}^{2} d_{e f}\left(\tau^{\prime}\right)}{d_{f} R^{2}\left(\tau^{\prime}\right)} \frac{\partial}{\partial \xi}\left[\xi^{2} \frac{\partial \psi}{\partial \xi}\right]
\end{aligned}
$$

Em relação aos mecanimos de transferência de calor, este modelo considera que o calor é transferido da corrente de ar para a interface ar-sólido por convecção, e da interface para o interior da amostra por condução. Para a transferência de massa, considerou-se que a água é transferida por difusão para a superfície e da interface ar-sólido para o ar de secagem por convecção. A Equação 1 está submetida à condição inicial na qual assume-se que a temperatura do sólido esférico é uniforme em todo o seu conteúdo antes do início do processo de secagem. Uma condição de contorno considera que na superfície do sólido, o fluxo de calor se iguala ao fluxo convectivo. Finalmente, uma condição de simetria assume que o fluxo de condução de calor no centro da esfera é nulo, pois possui a mesma magnitude para qualquer valor das dimensões angulares. Uma análise similar pode ser feita para avaliar a transferência de massa. As condições inicial, de contorno e de simetria são dadas pelas Equações 3, $4,5,6,7$ e 8 . 


$$
\begin{aligned}
& \theta=1 \text { para } \tau=0, \forall \xi \\
& \left.\frac{\partial \theta}{\partial \xi}\right|_{\xi=1}=-\left.3 B i \theta\right|_{\xi=1}, \tau \geq 0, \xi=1 \\
& \frac{\partial \theta}{\partial \xi}=0 \text { para } \tau \geq 0, \xi=0 \\
& \psi=1 \text { para } \tau=0, \forall \xi \\
& \left.\frac{\partial \psi}{\partial \xi}\right|_{\xi=1}=-\left.3 B i_{m} \psi\right|_{\xi=1}, \tau^{\prime} \geq 0, \xi=1 \\
& \frac{\partial \psi}{\partial \xi}=0 \text { para } \tau^{\prime} \geq 0, \xi=0
\end{aligned}
$$

Nas equaçoes de 1 a $8, \theta, \xi$, $\tau$, $\tau$ 'e $\psi$ são variáveis adimensionais. O número de Biot para a transferência de calor é calculado de acordo com a definição de resistência à convecção pela resistência à condução. Neste trabalho, considerou-se que a transferência de calor é a etapa limitante para o processo. Usou-se, portanto, o número de Biot modificado descrito por Chen e Peng (2005) que contabiliza a energia necessária para a evaporação de água, conforme Equação 9. O número de Biot para a transferência de massa é calculado de acordo com Crank (1975).

$$
B i^{*}=B i-\frac{\Delta H_{L} S_{v}}{\left(T_{a r}-T\right)} x \frac{L}{k}
$$

$\mathrm{Na}$ Equação 9, $\Delta \mathrm{H}_{\mathrm{L}}$ é o calor latente de vaporização da água, $\mathrm{S}_{\mathrm{v}}$ é fluxo de densidade de massa, T é a temperatura, L é o comprimento especifico da amostra e k é a condutividade térmica do material. $\mathrm{O}$ número de Biot modificado é menor do que o tradicional, reduzindo o valor da derivada do adimensional $\theta$ pelo adimensional espacial $\xi$, conforme Equação 4. Devido à necessidades de propriedades específicas da amostra, a difusividade e a condutividade térmica foram determinadas por meio de relações empíricas descritas por Choi e Okus (1986). Dados para a difusividade mássica foram encontradas na literatura.

No que diz respeito à metodologia numérica, foi utilizado o método das diferenças finitas para discretizar o sistema de equações do modelo para cada ponto nodal em uma malha estruturada para cada caso, incluindo as condições de contorno e de simetria. $\mathrm{O}$ sistema de equações resultante foi integrado na dimensão temporal pelo método de Runge-Kutta e o programa Matlab® foi utilizado para solução numérica e simulação. 


\section{RESULTADOS E DISCUSSÕES}

\subsection{Dados Experimentais}

Neste trabalho, foram analizadas dois tipos sementes de macadâmia: sementes verdes e maduras com quebra de dormência sem rachadura e com e sem broto. Ambos os tipos de sementes foram secadas nas mesmas condições, em uma estufa a $70^{\circ} \mathrm{C}$. As Figuras 3 e 4 mostram o comportamento típico do raio no decorrer do período de secagem.

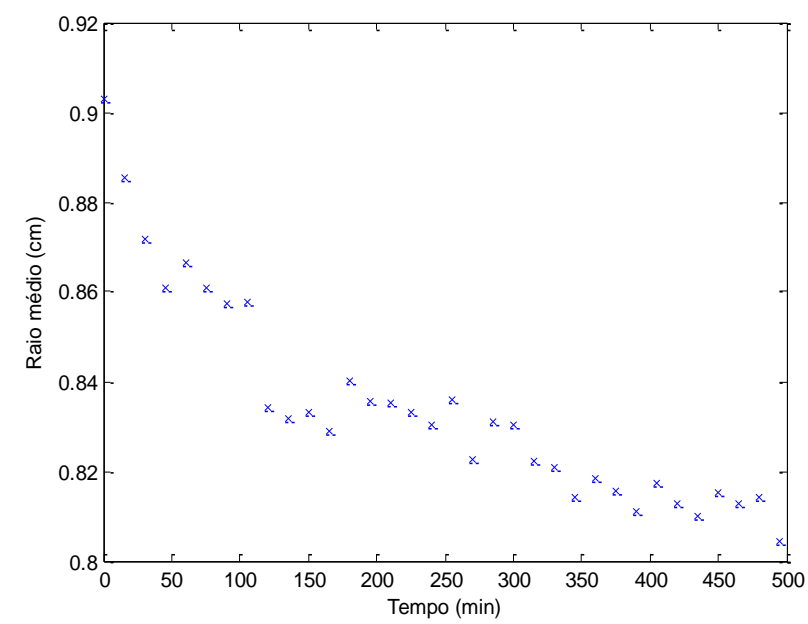

Figura 3: Redução do raio durante a secagem em sementes verdes com quebra de dormência sem rachadura e sem broto

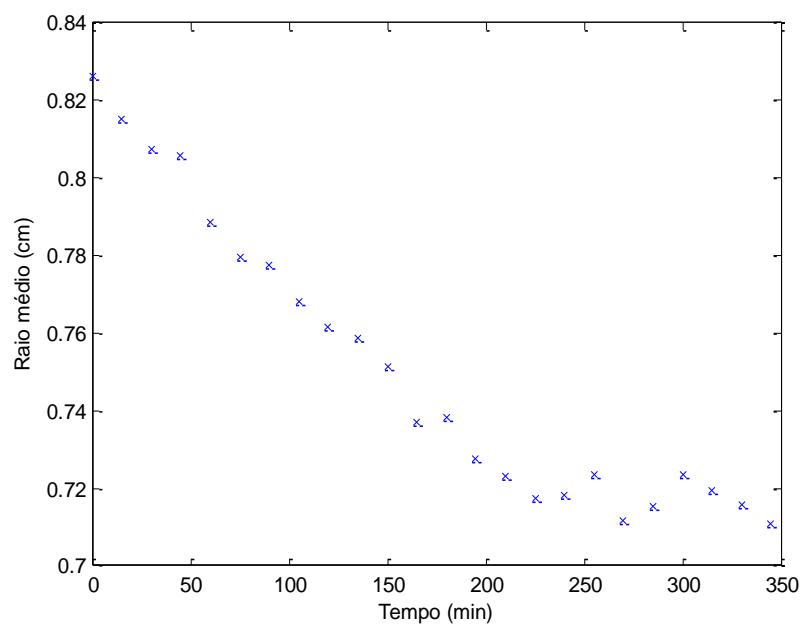

Figura 4: Redução do raio durante a secagem em sementes maduras com quebra de dormência sem rachadura e sem broto

A redução do raio da amostra ocorre devido à perda de massa durante a secagem. A migração de água do interior para a superfície causa uma deformação nas estruturas internas da amostra e, consequentimente, seu encolhimento. A partir da figura 3 observa-se uma redução acentuada do raio durante os primeiros 200 minutos de secagem. Após este período, redução torna-se lenta e tende a 0,81 $\mathrm{cm}$. Na figura 4 este valor se aproxima de $0,71 \mathrm{~cm}$.

O comportamento da densidade do fluxo de massa para ambas as sementes é descrito pelas Figuras 5 e 6 . Na Figura 4, observa-se que o primeiro período decrescente de secagem é mais longo em relação à Figura 5. Isso é explicado pelos conteúdos inciais diferentes de água das sementes. 


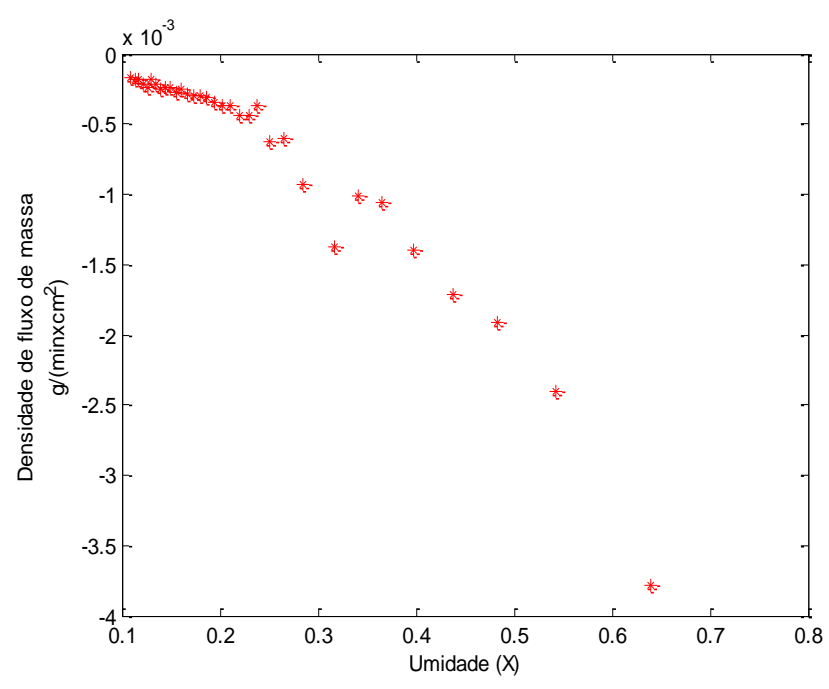

Figura 5: Densidade de fluxo de massa em função da umidade em sementes verdes com quebra de dormência sem rachadura e sem broto

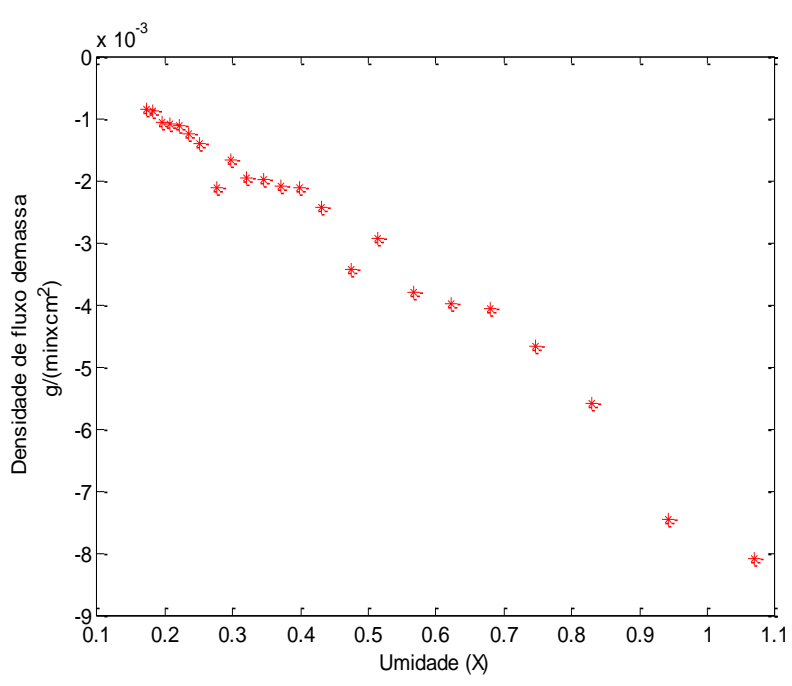

Figura 6: Densidade de fluxo de massa em função da umidade em sementes maduras com quebra de dormência sem rachadura e sem broto

Pela análise da inclinação da curva no gráfico de densidade de fluxo de massa por umidade, a secagem das sementes descritas neste trabalho caracterizou-se por dois períodos predominantes de taxa descrescente de secagem. Para a fase de taxa decrescente de secagem, o produto não se comporta como se estivesse recoberto por uma fina camada de água (Guimarães, 2005), pois a migração de água do interior do sólido para a superfície é insuficiente para compensar a perda de umidade por evaporação. No primeiro período drecescente ainda há umidade livre presente na amostra. Normalmente ocorre a formação de aglomerações descontínuas de água livre por toda a superfície (Zhang, 1999). O conteúdo de água livre na superficie influencia os coeficientes de tranferência de calor e de massa, causando uma redução umidade mais acentuda (pelo existência de água livre na superfície) e um aumento de temperatura um pouco mais lento em relação ao segundo período decrescente de secagem.

O segundo periodo decrescente secagem caracteriza-se pela ausência de água livre na superfície da amostra. A troca de calor não é mais compensada, conseqüentemente, a temperatura do produto aumenta mais rapidademente e tende assintoticamente à temperatura do ar. Durante todo este período o fator limitante é a migração interna de água (Park, 2007). As Figuras 7 e 8 mostram a perda de umidade durante a secagem. Em ambas figuras, é possivel verificar dois períodos predominantes diferentes de secagem. A diferença nos tempos em que esses períodos começam ou terminam é devido às diferenças das propriedades iniciais das amostras. 


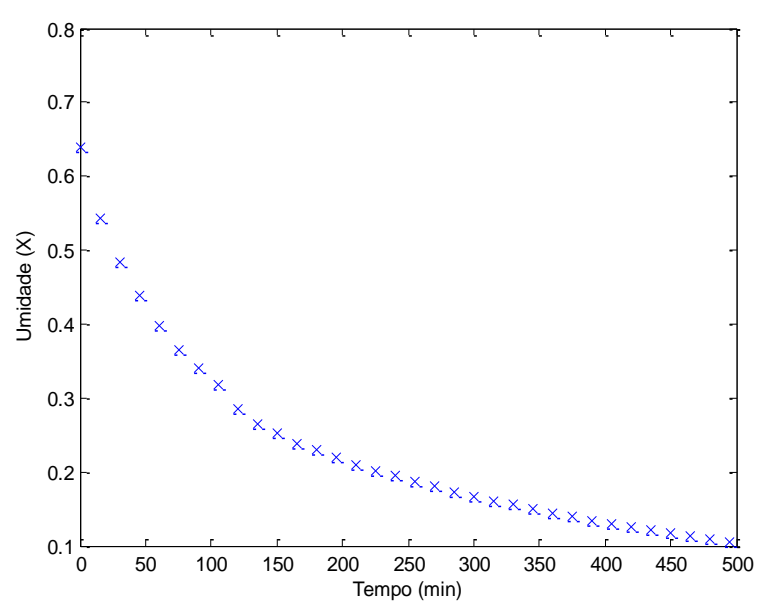

Figura 7: Perda de umidade durante a secagem em sementes verdes com quebra de dormência sem rachadura e sem broto

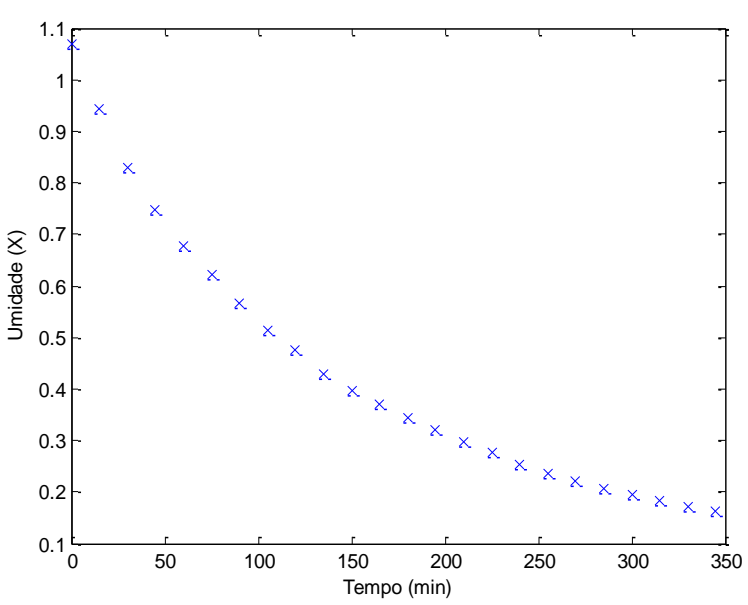

Figura 8: Perda de umidade durante a secagem em sementes maduras com quebra de dormência sem rachadura e sem broto

\subsection{Simulações}

As simulações foram feitas de acordo com os dados da secagem das sementes verdes com quebra de dormência sem rachadura e sem broto. As Figuras 9 e 10 mostram os resultados típicos da simulação feita no programa Matlab®. A figura 9 descreve o comportamento da temperatura durante os dois períodos de taxa decrescente de secagem. Esta figura foi gerada de acordo com a Equação (1) e suas condições inicial de contorno com o número de Biot modificado.

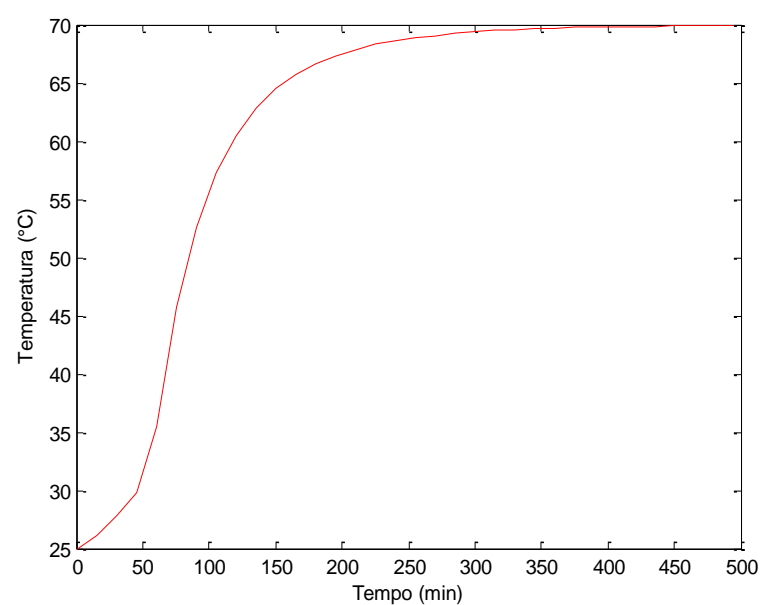

Figura 9. Variação da temperatura no decorrer do tempo de secagem

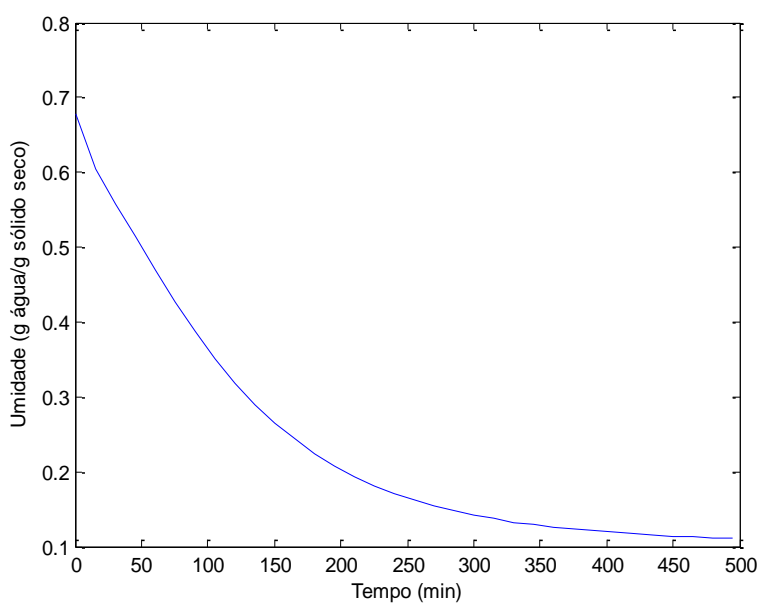

Figura 10. Variação da umidade no decorrer do tempo de secagem 
Durante aproximadamente os primeiros de 50 minutos de secagem, observa-se que a temperatura da amostra aumenta de forma gradual. Este intervalo de tempo está contido no primeiro período de taxa decrescente de sacagem, em que há aglomerados descontínuos de gotas de água pela superfície que utilizam parte da energia fornecida pelo ar para a mudança para a fase vapor. Estes aglomerados retardam a velocidade com que a temperatura aumenta durante o processo. Após 50 minutos, o processo entra no segundo período de taxa decrescente de secagem. Como não há mais umidade na superfície da amostra, a temperatura aumenta rapidamente e tende assintoticamente à temperatura do ar. A temperatura da amostra se estabiliza em $69.8^{\circ} \mathrm{C}$ com aproximadamente $400 \mathrm{~min}$ de secagem. Nesta etapa, toda a energia fornecida pelo ar de secagem é utilizada para aquecer a amostra.

A Figura 10 representa o comportamento da umidade da amostra no decorrer do tempo de secagem. Esta foi gerada de acordo com a Equação (2) e suas condições inicial e de contorno. A umidade da amostra se estabiliza em $0.11 \mathrm{com}$ aproximadamente 400 minutos. O modelo utilizado na simulação de transferência de massa representou, de forma bem aproximada, os dados experimentais. Uma melhor aproximação pode ser feita com inclusão das dimensões angulares ao modelo e a determinação de algumas propriedades específicas da amostra em laboratório. Este modelo pode ser adaptado para a secagem de sementes esféricas em geral e de outros produtos nacionais, como a pimenta rosa.

\section{CONCLUSÃO}

O modelo matemático, utilizado para representar a transferência de massa no sólido, que considera o número de Biot global, foi capaz de avaliar o perfil de umidade da amostra. O modelo de transferência de calor, que considerou o número de Biot modificado, foi capaz de representar a elevação gradual da temperatura durante os primeiros 50 minutos de secagem devido a existência de umidade na superfície da amostra. Este modelo sugere que o calor latente de vaporização da água deve ser contabilizado para uma melhor aproximação do fenômeno físico. Este trabalho contribuiu para a compreensão do fenômeno de transferência de calor e de massa de uma noz de macadâmia única. Numa posterior etapa, pretende-se adaptado para a etapa de torrefação do fruto.

\section{NOMENCLATURA}

$\begin{array}{ll}\text { Bi } & \begin{array}{l}\text { número de Biot } \\ \text { difusividade de massa } \\ \mathrm{d}\end{array} \\ \Delta \mathrm{H}_{\mathrm{L}} & \begin{array}{l}\text { calor latente de vaporização } \\ \text { condutividade térmica }\end{array} \\ \mathrm{k} & \text { comprimento específico } \\ \mathrm{L} & \text { raio da amostra } \\ \mathrm{R} & \text { densidade de fluxo de massa } \\ \mathrm{Sv} & \text { temperatura } \\ \mathrm{T} & \text { Umidade } \\ \mathrm{X} & \end{array}$




\subsection{Símbolos}

$\begin{array}{ll}\xi & \text { raio adime } \\ \tau & \text { tempo adiin } \\ \tau^{\prime} & \text { tempo adiin } \\ \theta & \text { temperatura } \\ \psi & \text { umidade a } \\ \text { 5.2 Subscritos } & \\ & \\ \text { e } & \text { equilíbrio } \\ \text { ef } & \text { efetivo } \\ \text { f } & \text { final } \\ \text { s } & \text { seco } \\ 0 & \text { inicial }\end{array}$

\section{REFERÊNCIAS}

ARRIECHE, L. S. Modelagem Matemática do Processo de Secagem, por Convecção Forçada, de Sistema Simuladores de Alimentos Esféricos e Deformáveis. 2007. 129f. Tese (Doutorado)- Centro de Ciências Exatas e de Tecnologia, Universidade Federal de São Carlos, São Carlos, 2007.

CORRÊA, P. C.; RESENDE, O.; MARTINAZZO, A. P.; GONELI, A. L. D.; BOTELHO, F. M. (2007) "Modelagem Matemática Para a Descrição do Processo de Secagem do Feijão (Phaseolus Vulgaris L.) em Camadas Delgadas". Eng. Agríc., Jaboticabal, v.27, n.2, p.501-510, maio/ago 2007.

CHEN, X. D. AND PENG, X. F. Modified Biot Number in the Context of Air-Drying of Small Moist Porous Objects, Dry. Tech., 23(1-2), 83-103, 2005.

CHOI, Y., M.R. OKOS. 1986. Effects of Temperature and Composition on the Thermal Properties of Foods. In Food Eng. Proc. Applic, 1:93-101. London: Elsevier Applied Science Publishers.

CRANK, J. The mathematics of diffusion. 2. ed. England: Oxford University Press, 1975.

GUIMARÃES, D. S. Desenvolvimento de módulo computacional para a secagem estacionária de sementes. 2005. Tese (Doutorado) - Universidade Federal de Pelotas, Faculdade de Agronomia Eliseu Maciel, Programa de Pós-Graduação em Ciência e Tecnologia de Sementes.

PARK, Kil Jin; ANTONIO, Graziella Colato; OLIVEIRA, Rafael Augustus De. Conceitos de processo e conceitos de secagem. Ct\&ea. Campinas, p. 55. 01 mar. 2007.

ROBERTS, J, S; TONG, C, H. Drying Kinetics of Hygroscopic Porous Materials Under Isothermal Conditions of the Diffusion Model on Hygroscopic Material, International Journal of Food Properties, 6(1), 165-180, 2003.

ZANG, Zhe; YANG, Shiming; DENGYING. Mechanism and mathematical model of heat and mass transfer. J. Chem. Ind. and Eng. China, p. 52. 05 jun. 1999. 